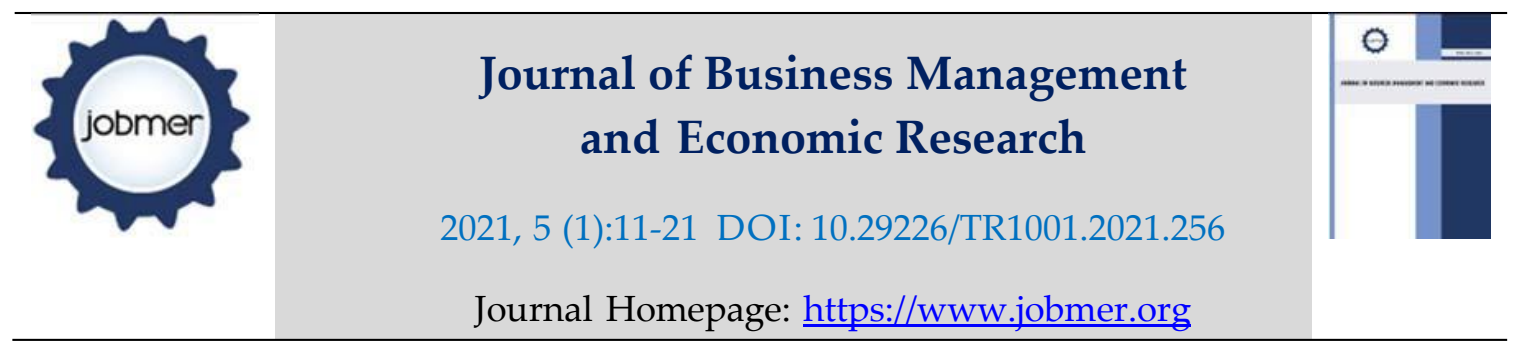

\title{
The role of Cultural Values and Relationship Marketing Programs in Promoting Customer Satisfaction
}

\author{
Benon Nabimanya Muhumuza \\ Department of Marketing and Management, Makerere University Business School, Kampala, Uganda \\ bmuhumuza@mubs.ac.ug
}

ORCID Number: 0000-0002-9168-721x

Ernest Saina

Department of Economics, School of Business and Economics, Moi University, Nairobi, Kenya Ernestsaina2017@gmail.com

ORCID Number:0000-0002-6939-1359

Hassan Bashir*

Department of Business Administration, Makerere University Business School, Kampala, Uganda

bhassan@mubs.ac.ug

ORCID Number: 0000-0003-2367-4094

\begin{abstract}
This paper investigated the mediation effect of relationship marketing programs on the relationship between cultural values and customer satisfaction in the hotel industry of Uganda. This study was relevant because the current era of growing competition and changing customer expectations within the hotel industry, compels hotels to devise strategies to attain a competitive advantage. Cultural values enhance and guide relationship-marketing programs which increase customer satisfaction. A quantitative survey design focusing on hotel customers was adopted to investigate the envisaged linkage between cultural values, relationship-marketing programs and customer satisfaction. The results of the study indicated that relationship-marketing programs partially mediates the relationship between cultural values and customer satisfaction. The study results provide a reason for hotel managers to devote more resources towards cultural values in a bid to enhance relationship-marketing programs, which resonates customer satisfaction. The results of the study support the idea that cultural values through relationship marketing programs generate a sustainable psychological satisfaction for customers and a high market share for the organization, more importantly in an environment that is multi-cultural in nature. The study recommends hotel managers to regularly consider the multi-cultural faceted society when designing relationship-marketing programs in order to build a long-term relationship with customers. As evidenced in this study, it is of great importance to cultivate cultural values in order to enhance relationshipmarketing programs, an aspect that is vital in boosting customer satisfaction. Theoretically, the study extends the adaptability of social exchange theory on customer satisfaction by expounding relationship marketing in enhancing customer satisfaction.
\end{abstract}

Keywords: Cultural values, Relationship marketing programs, and customer satisfaction. 


\section{Introduction}

Relationship marketing programs and customer satisfaction are key concepts in the changing paradigm of relationship marketing in business-to-business markets (B2B) as well as business-toconsumer markets (B2C). Scholarly views on promoting customer satisfaction rotate around relationship marketing programs like financial, social, structural and confidence building (Lo, 2012). These programmes are of great importance in securing customer satisfaction in the current modern marketing practices where customer preference is the springboard for the organization's success. In the practitioners' spheres, relationship marketing programs are viewed as a business philosophy which propels customers' comportment towards the service provider and results into satisfaction (Huang, 2015). Customer satisfaction calls for regular monitoring of customer behaviors as customers' tastes and preferences keep changing. In building the philosophy to maximize customer satisfaction, cultural values are key to success. This is why Lima and Fernandes (2015) notes that attitudes, cognitions, emotions, and behaviors are built on one's values yet personal values influence behavioral decisions and customer satisfaction (Mohsan, Nawaz, Khan, Shaukat, \& Aslam, 2011). This is because service encounters involve learned and stable behavioral patterns from customers.

Many studies have as well advanced the importance of relationship marketing programs in building customer satisfaction (Berry, 1995; Huang, 2015; Morgan \& Hunt, 1994; Wilson, 1995). Relationship marketing (RM), which focuses on the ways of building, developing, and maintaining successful relational exchanges with customers (Morgan \& Hunt, 1994), can be regarded as one of the best strategies to gain profitability and competitive advantage for firms and increase customer satisfaction (Morgan \& Hunt, 1994). More research work has also been undertaken to find out the impact of marketing actions as well as heterogeneity of customer satisfaction (Lo, 2012). From the empirical point of view, there is a need to explore factors that enhance effectiveness of relationship marketing programs in order to attain customer satisfaction (Matthews \& Watchravesringkan, 2014). It is upon this background that the present study focuses on these limitations by investigating the effects of cultural values on relationship marketing programs and customer satisfaction of Ugandan hotels' customers in their longterm relationships. Specifically, the study examines the nature of cultural values of hotel customers and how this re-energizes relationship-marketing programs to achieve customer satisfaction.

In addition, the study examines the potential contribution of cultural values in broadening the theoretical understanding of the determinants of relationship marketing programs and customer satisfaction. The results of this study will be useful in guiding service providers of the Ugandan hotels the best ways of improving customer services in order to achieve business profitability and sustainability as a result of customer satisfaction. The outcome of this study will be the accelerated growth of the hotel industry and subsequently the tourism sector. According to the UHOA publication (2018), the hotel industry is one of the fastest growing industries accounting for more than one third of the total country's services trade and contributing 3.7\% (US \$2 million) of the total GDP (UBOS' report, 2019).

\section{Literature Review}

\section{Theoretical underpinning of the study}

This study is anchored on the social exchange theory (Das \& Teng, 2002). The theory integrates relational contract theory to develop a framework of buyer-seller relationships in which exchanges lie on a continuum from discrete to relational transaction. Social exchange theory evolved as a result of scarcity of resources which prompted actors to engage one another in order to obtain valuable inputs (Das \& Teng, 2002). Based on the theory's argument that social exchanges may or may not involve extrinsic benefits with an objective of economic value, this study focuses on the physical buying context and the pertinent factors for social exchange such as reciprocity, reputation, trust, and seller creativity. The theory explains that individuals are subject to internal conflict between the need for inclusion and similarity and the need for a difference and distinction. 
Social exchange theory explains customer satisfaction in four perspectives. The first perspective involves social programs which are espoused to have a positive effect through interpersonal interaction with relationship variables among which satisfaction is inclusive. The second perspective entails financial programs whereby the service provider uses economic benefits such as price, discounts and other financial incentives for regular customers to secure their loyalty through customer satisfaction (Lin, Weng \& Hsieh, 2003). In this perspective, the theory combines the elements of transactional cost theory in enhancing relationship value hence customer satisfaction. The third perspective emphasizes that structural programs should enable a business to enhance customer relationships by offering solutions to customer problems in the form of service-delivery systems, rather than remaining dependent upon the relationship building skills of individual service providers (Lin et al., 2003).

The fourth perspective brings out confidence programs. Lima and Fernandes (2015) define confidence programs as perceptions of reduced anxiety and comfort in knowing what to expect in the service encounter. This in turn decreases the risks in services and builds trust which is key in providing feelings of assurance to customers and improves customer satisfaction. Some writers argue that besides the core benefits, relationships are central to the success of sustaining relationship value with the service provider (Chen et al., 2012). It is upon this background that social exchange theory becomes relevant in analyzing this relationship in this study.

\section{Cultural values and customer satisfaction}

According to Tigre Moura, Gnoth, and Deans (2015), cultural values are the deepest and most relevant aspect of a cultural manifestation, albeit intangible. These values characterize broad tendencies which make people behave in a certain way when dealing with feelings or evil versus good, dangerous versus safe, and moral versus immoral. Cultural values are learned in the initial stages of life and make customers prefer certain products to others. According to Chen, Chiang, and Storey (2012) customers of different cultural backgrounds may have different perceptions of and reactions to certain products or services. Some scholars believe that cultural differences can be grouped into four areas (Schuckert, Liu, \& Law, 2015). Differences in perceptions of service, differences in expectations, differences in emphasis on demand for services, and differences in complaints. From such assertions, it is evident that cultural values influence customer satisfaction.

From the marketing literature, consumer satisfaction involves a comprehensive array of events and cultural factors have emerged to be of great importance in influencing consumer's decisions (Schuckert et al., 2015). According to Tigre et al. (2015), culture shapes consumer's desires and the way they respond to goods and services. From such assertions, it is evident that cultural values have an impact on customers' choice of services as well as products, which influences maximization of customer satisfaction. According to Schuckert et al. (2015), culture nurtures different views of what is desirable and meaningful to do with incomes. It also influences the processing strategies and thinking styles of consumers thus leading to customer satisfaction.

\section{The mediation effect of relationship marketing programs between cultural values and customer satisfaction}

Relationship marketing programs are defined as those activities that a service provider needs to undertake in an effort to enhance a good relationship with the customer (Schuckert et al., 2015). It is believed that there are four types of relational programs; financial, social, structural and confidence programs that are considered important in securing customer satisfaction. Relationship marketing programs is one component in marketing that is vital in shaping and enhancing customer satisfaction. It is also an important variable in understanding the development and maintenance of customer- service provider relationship. It should be noted that there has been a number of studies in the service sector enunciating antecedents of relationship marketing programs and the consequences in the service industry. Influential factors include variables related to hotel management services like service offering in 
terms of menus reflecting a country's regional cultural diversity, quality and pricing as well. The study focuses on how cultural values such as; shared values, identity and beliefs influence relationship marketing programmes to maximize customer satisfaction.

Customer satisfaction is the key driver for any organization to sustain its operations in the current competitive era. Service providers need to recognize the importance of their customers and design the services in a way that promotes maximum possible customer satisfaction (Amin, 2015). With the change in the lifestyles of the customers, a significant shift has been observed in the demands and expectations of the customers. Customers in the hotel sector are no longer ready to be treated as one demographic category and tolerate a 'one-size-fits all' mentality. This calls for service organizations to tailor the products or services to customers' needs and requirements in order to have a competitive advantage in the market (Lima \& Fernandes, 2015). Such a situation profoundly necessitates inclusion of cultural values to maximize customer satisfaction.

Customer satisfaction is considered as the final pillar in modern marketing. In principle, customer satisfaction is the wheel that keeps the operations of service firms moving. It is considered as the main component of the firm's success (Yusof, Awang, Jusoff, and Ibrahim, 2017). Therefore, customer satisfaction is the difference between the expectations of the customers before receiving the services and perceptions of the customers after receiving the services. Customer satisfaction mainly depends on the build-up of the perceived value to which the customers have concerning a product or service (Amin, 2015). In this paper, customer satisfaction is operationalized as the customer's perceived performance, expectation, disconfirmation and satisfaction of customers experience from the purchase of a product or service. Customer satisfaction is presumed to be closely associated with such positive relationship marketing programs as predictors, with a positive effect on long-term relationship. Azizi, Bagherzadeh, and Mombeini (2014) studied the impact of relationship marketing components among which included; dependency, trust, commitment, norms based on cooperation and conflict management on customer satisfaction in the lifecycle of the relationship. It was found that trust and dependency associate with satisfaction in the steps of building and maturity of the relationship while commitment associates only with the maturity step of satisfaction.

The conceptual arguments of this study and the hypotheses derived from the theoretical review are summarized in Figure I.

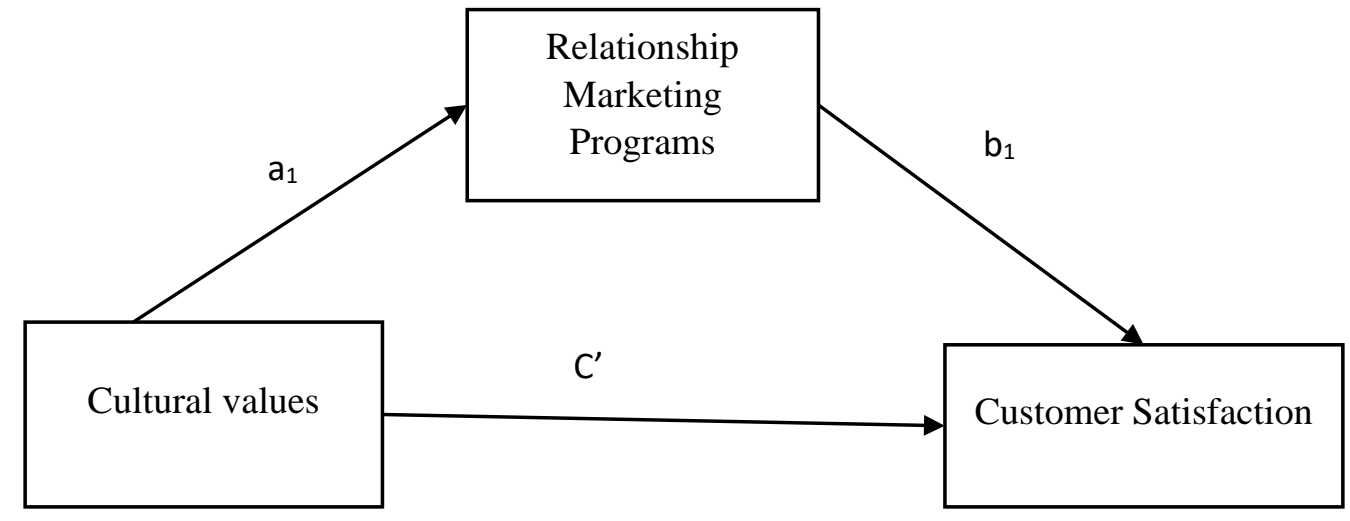

Figure 1. Model and hypothesized relationships

Hypotheses adopted for the study

HI: CI: Cultural values positively and significantly relate to customer satisfaction

H2: a1: Cultural values are positively and significantly related to relationship marketing programs 
H3: b1: there is a positive and significant relationship between relationship marketing programs and Customer Satisfaction

H4: a1 ${ }^{*}$ b1: Relationship marketing programs mediate the relationship between cultural values and Customer Satisfaction

\section{Methodology of the Study}

\section{Research design, study area and sampling}

The study adopted a cross- sectional approach. It was quantitative in nature where hotel customers from different ethnic groups participated. The study sought to describe and establish associations among key study variables, namely, cultural values, relationship marketing programs and customer satisfaction in the service sector. This design is appropriate since it allows inferences to be made to the broader populations and permit generalizations of findings to real life situations, thereby increasing the external validity of the study (Neuman, 2007). A sample of 384 out of 28,500 daily walk-in and resident hotel customers of 19 out of 62 registered hotels in Uganda was considered (Uganda hotel owners' association report 2018; Krejcie and Morgan, 1970). These were proportionately selected from the four regions of Uganda (East, West, North and Central region) based on the registration categories of Five-star, Four-star, Three-star and Two-star, using stratified and simple random sampling approaches (Faroughian et al., 2012).

\section{Measurement of variables Cultural values}

Cultural values were measured by adopting tools developed by Lo (2012). These scholars measured cultural values based on four dimensions; openness to change, conservation, self-enhancement, and self-transcendence values. According to Schuckert et al. (201), openness to change values focus on readiness for new ideas, activities, and experiences. Conservation values denote restricting one's behavior, emphasizing stability, and maintaining the status quo (thus avoiding change). Selfenhancement values pertain to an individual's pursuing of his or her own interests. Self-transcendence values entail going beyond one's own interests and focus on those of others. To tap the four dimensions as per Lo (2012) the study was anchored on a 5-point Linkert scale of $1=$ "Strongly disagree to $5=$ "Strongly agree.

\section{Relationship marketing programs}

Research on relationship marketing programs is still ongoing with not much agreement among the scholars regarding the most appropriate way to measure relationship marketing programs. This is because these programs keep on changing based on circumstances. Nevertheless, the study adopted a measurement tool developed by Luu et al. (2018). A Five-Point Likert-type scale anchor was used where respondents were asked to indicate their level of agreement with each item. 1 represented' 'Strongly Disagree" and 5 represented "strongly agree"

\section{Customer satisfaction}

Customer satisfaction was measured by adopting a tool used by Caruana (2002) and Eugene, et al. (1994) to study customer satisfaction in retail banking. A subjective assessment of the hotels' efforts to maximize customer satisfaction relative to the competitors in the industry along the three dimensions of customer satisfaction; expectations, disconfirmation of expectations, and perceived performance was adopted. Customer satisfaction items responses were summated to create an aggregated score (Uebersax, 2006). To tap the three dimensions of customer satisfaction, the study was anchored on a 5-point Linkert scale of $1=$ "Strongly disagree to $5=$ "Strongly agree.

\section{Validity and Reliability of the Research Instrument}

Reliability of the items for the study was assessed by determining the composite reliability. This was preferred and adopted because it is a generally more robust measure of reliability than the other approaches (Hair et al., 2010). The minimum desired of the composite Reliability is .700. The researcher 
also tested for convergent validity using the Average Variance Extracted (AVE). The minimum AVE, for the items to have satisfied the Convergent Validity Condition is .500 and we note from the values of the AVE in table I that the lowest value was .634 and the highest was .690 . The composite reliability indices were also above the threshold of .70 . The results therefore show that the tool was valid and reliable hence worth taking for further analysis.

Table I: Reliability and Validity of the Research Instrument

\begin{tabular}{lccc}
\hline Variable & $\begin{array}{c}\text { Composite } \\
\text { Reliability }\end{array}$ & $\begin{array}{c}\text { Average Variance } \\
\text { Extracted (AVE) }\end{array}$ & $\begin{array}{c}\text { Variance Inflation } \\
\text { Factors }\end{array}$ \\
\hline Relationship Marketing Programs & .812 & .685 & 1.167 \\
Cultural Values & .817 & .690 & 1.173 \\
Customer Satisfaction & .838 & .634 & 1.443 \\
\hline
\end{tabular}

\section{Data analysis and presentation}

In this study, data was analyzed using SPSS and the SMART-PLS software. While SPSS tested correlations, regressions and the mediation effect using the SPSS Macros-developed by Hayes (Hayes, 2009), SMART-PLS was used to assess the Average Variance Extracted, Collinearity and the composite reliability measurements for each variable. The multi-collinearity was assessed using the Variance Inflation Index (VIF). This tool inspects whether the items are distinct from the perspective of the research respondents (Gareth, 2017). High VIF would lead to misleading results and there would be very high correlations which are not a result of the effect of one variable on another but a result of anomalies in the research instrument. The Variance Inflation Index (VIF) threshold, beyond which the tool should be non-reliable, is 5.000. However, for this data set, the results in table I show that there was no collinearity problem with the data. The Variance Inflation Factors (VIF) were less than 5.000 and the researcher therefore considered these items to be quite relevant for the measurement of the variables since each of them had an acceptable value of the Variance Inflation Factors (VIF).

\section{Data Presentation and Interpretation of findings \\ Demographic Characteristics of the sampled respondents}

The results showed that with regard to gender, the sample was dominantly comprised of males $(60.4 \%)$ though there were also females that featured in the sample $(39.6 \%)$. This is an indication that the study data are mainly from men as compared to women. The results also indicate that male customers are more likely to be in these hotels owing to the corporate and the lifestyle aspects, which usually see men hanging out with friends and peers while women are more mindful of the family as and when they get some free time off their work schedules. The age distribution show that over $70 \%$ of respondents were in the age bracket of 21- 50-year with those above 50 years being the minority. In terms of education background, $36.6 \%$ of the respondents were holders of a bachelor's degree. Other categories of respondents were also represented for instance those with Diplomas were $25.5 \%$ and those with postgraduate qualifications were $22.5 \%$. The findings in this case show that the respondents were quite literate and could ably understand the questions that were raised in the questionnaire, and thus give more reliable and credible answers for the study.

\section{Correlation analysis}

Pearson (r) correlations coefficient was used to examine the relationship between study variables. This statistic was chosen rather than other coefficients such as the Point-Biserial correlation coefficient or the Spearman Rank Correlation Coefficient owing to the fact that the data was measured using a Likert scale for all variables and none of them was dichotomous (Wilcox, Winn, \& Fyvie-Gauld, 2005). Table II presents correlation findings of study variables. 
Table II: Pearson Correlations Coefficient

\begin{tabular}{lccccc}
\hline & Mean & SD & 1 & 2 & 3 \\
\hline Relationship Marketing Programs-1 & 3.706 & .641 & 1.000 & & \\
Cultural Values-2 & 3.651 & .779 & $.517^{* *}$ & 1.000 & \\
Customer Satisfaction-3 & 3.852 & .616 & $.501^{* *}$ & $.481^{* *}$ & 1.000 \\
**. Correlation is significant at the 0.01 level (2-tailed). & & & & \\
\hline
\end{tabular}

Table III: Mediating effect of relationship marketing programs on the relationship between cultural values and Customer satisfaction

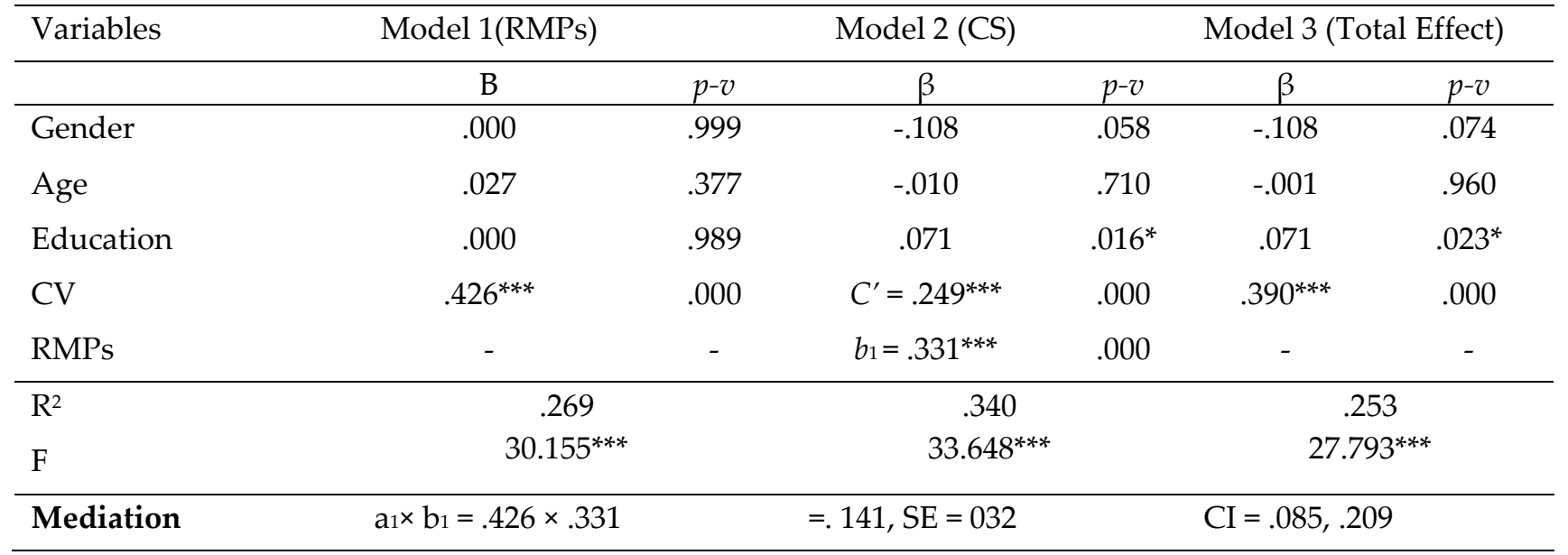

Note: ${ }^{*} \mathrm{p}<.05,{ }^{* * *} \mathrm{p}<.001$

The results in table II show a significant and positive relationship between Relationship Marketing Programs and both cultural values $\left(\mathrm{r}=.517^{* *}, \mathrm{p}<.01\right)$ and customer satisfaction $\left(\mathrm{r}=.501^{* *}, \mathrm{p}<.01\right)$. It was noted that cultural values have a weaker significant relationship with Customer Satisfaction $\left(r=.481^{* *}, \mathrm{p}\right.$ $<.01)$ than the relationship with the Relationship Marketing Programs. This implies that satisfaction of customers is much more likely to be realized when management is committed to the relationship marketing programs such as the social, structural and financial programs. To determine the causation and the mediation effects, the hierarchical regression model in table III above is presented.

Regression Analysis

H1: Cultural values positively and significantly relate to customer satisfaction

Regression analysis results in table III confirmed that the relationship between cultural values and customer satisfaction is positive and statistically significant $\left(\beta=.249^{* * *}, \mathrm{p}<.001\right)$. These results indicate that when hotels offer services that ring a cultural note to the patrons, the customers rate the hotel as one that offers a gratifying and a worthwhile hotel experience. These results support the first hypothesis.

H2: Cultural values positively and significantly affect Relationship Marketing Programs

The regression model estimates indicated a positive and significant relationship between the cultural values and relationship marketing Programs $\left(\beta=.426^{* * *}, \mathrm{p}<.001\right)$. These results indicate that hotels which put in place efforts to promote the cultural diversity of their customers, such as preparing the local dishes that the clientele are accustomed to in their native areas of upbringing, shall have greater 
success in realizing the value for money from their relationship marketing programs. These results support the second Hypothesis.

\section{H3: Relationship marketing programs are positively and significantly related to customer satisfaction}

The study set out to further establish the nature of the relationship between relationship marketing programs and customer satisfaction. The results show that Relationship Marketing Programs are significantly and positively related to customer satisfaction $\left(\beta=.331^{* * *}, \mathrm{p}<.001\right)$. The results show that Relationship Marketing Programs such as the financial and the social efforts of the hotels ultimately bring about customer satisfaction. Social interventions in this case, would for instance be implemented by using social activities to promptly demystify new service offerings, address customer complaints and the result would be the delight and satisfaction of the customers. The results are a clear vindication that relationship-marketing programs can easily be exploited by the hotel management to enhance satisfaction of customers with the service offerings.

H4: Relationship marketing programs mediate the relationship between Cultural values and customer satisfaction

The study further set out to establish the nature of the mediating effect of relationship marketing programs in the relationship between cultural values and customer satisfaction. The results indicated that there is a significant and positive relationship between cultural values, relationship marketing programmes and customer satisfaction. In model 2 of table III, the results indicated that cultural values and the relationship marketing programs are both significant predictors of customer satisfaction even when we introduced relationship-marketing programs in the equation. The results show that the direct effect of cultural values to customer satisfaction is significant (Beta $=.249^{* * *}$, sig. $<.001$ ) just like the indirect effect from cultural values - relationship marketing programs - customer satisfaction $(\mathrm{p}<.01)$. The reduction in the direct effect from .426 to .249 , is truly significant. The results show that the indirect effect is still significant as noted from the Confidence Interval levels $(C I=.085, .209)$, which shows that a zero was outside the confidence interval range. The results therefore show that relationship-marketing programs partially mediate the relationship between cultural values and customer satisfaction. The results further show that there is a significant total effect of cultural values on customer satisfaction $(\beta=$ $\left..390^{* * *}, \mathrm{p}<.001\right)$ and that the indirect path was statistically significant, yet the direct effect remained significant.

The findings highlight the need to exploit cultural values when enhancing relationshipmarketing programs if customer satisfaction is to be attained. The relationship that the customers have with the hotel management, once cultural values are incorporated in the service offering, will yield more customer satisfaction. The results also show that cultural values re-energize relationship-marketing programs which aspect propels customer satisfaction. The customers feel that they are part of the hotel and their views and cultural dimensions are taken seriously. As a result, customers attain a greater sense of contentment with the entire service offering of the hotel. Most of the behavioral studies in marketing on cultural values and customer satisfaction mediated by relationship marketing programs, have been mostly in developed countries and the focus has been on business to business. However, this study was carried out in an emerging economy focusing on business to consumers (B2C) in the service industry. It is important that the established findings of this study are harmonized with those of other established studies as a way of enhancing the power of the research model to predict customer satisfaction.

\section{Discussion}

This study examined the effect of cultural values of customers on relationship marketing programs and customer satisfaction in the hotel industry of Uganda. The significant effect of cultural values on relationship marketing programs is quite consistent with the current ideas on cultural values 
and extant empirical studies that examined similar studies such as Belias and Koustelios (2015). The current study results suggest that cultural values enhance relationship marketing programs' effectiveness which propels the attainment of customer satisfaction in the Ugandan hotels.

The study also showed that relationship marketing programs affect customer satisfaction. The findings agree with Huang (2015) who found that different relationship marketing programs drive customer satisfaction in Business to business (B2B) setting. Though the current study focused on business to consumer markets (B2C), the results show that relationship marketing programs such as financial, social, structural and confidence programs positively relate to customer satisfaction. This points to the need by the hotels to pay much attention to these relational programs if customer satisfaction is to be attained in the hotel industry.

This study focused on cultural values diffusion into relationship marketing programs development and design if customer satisfaction in the hotel sector is to be maximized. Ruiz-Equihua, Romero, and Casaló (2020) mention that culture influences all human behaviors, including consumption. However, understanding cultural influence on customer behavior is supported by the use of dimensional models that define patterns of behaviors, and, consequently, determine how individuals and groups function in a social network (Mooij \& Hofstede, 2010). Cultural values being positively related to customer satisfaction implies that hotels should exploit cultural values to tame customers thus customer satisfaction.

\section{Conclusion and managerial implications}

The study findings have broad and specific managerial implications for hoteliers in Uganda. At the broader level, the findings indicate that cultural values are central in enhancing relationshipmarketing programs. This implies that the hotel's management in Uganda can foster customer satisfaction by focusing on cultural values through embracing different cultural dimensions from different regions of the country. This approach of cultural diffusion is easier and more practical when developing relationship marketing program strategies in order to enhance customer satisfaction. In terms of specific implications, the results suggest that cultural values are critical and hoteliers in Uganda can differentiate themselves from competitors and create "switching barriers" for their customers.

Furthermore, the significant positive effect of cultural values on customer satisfaction is an indication that customers are inclined to their cultures and only hotels that can diffuse cultural values into their service delivery can hope to keep customers satisfied. In turn, this leads to market share growth and competitiveness.

It is widely known that in this competitive business environment the most important factor from hotel customers is customer satisfaction. Under such conditions, appropriate development and design of relationship marketing programs is viewed by the customers as hotels having interest in the welfare of the customers and in building a long-term relationship.

\section{Suggestions for Future Research}

The present study has limitations which future studies should strive to overcome. The data collection was limited to Ugandan hotels only. The findings presented in this study are based on the administered questionnaires within the Ugandan hotel sector. Thus, there is a need to carry out a similar study within different settings other than hotel sector in order to assess the similarities and differences that may prevail. It is also important to establish whether the findings of the study hold. Furthermore, there is need to carry out such a study in the East African region across member countries in order to assess whether there are any regional or country-specific characteristics with regard to the topic of investigation.

There is also needed to carry out further research using a mixed method approach by including a qualitative review such as in-depth interviews in order to gain further understanding of the phenomenon of cultural values. The mediation effect of relationship marketing programs in the relationship between 
cultural values and customer satisfaction should be tested by triangulating quantitative and qualitative approaches in order to confirm the quantitative findings of this study. In addition, the study collected data from only customers, there is need to include observations from the managers of different hotel as respondents in order to enrich the findings of the study to the academicians and practitioners.

\section{References}

Amin, I. (2015). A study of customer satisfaction towards hotel industry in Kashmir Valley. International Journal of Management Research and Reviews, 5(12), 1117.

Yusof, Y., Awang, Z., Jusoff, K., \& Ibrahim, Y. (2017). The influence of green practices by non-green hotels on customer satisfaction and loyalty in hotel and tourism industry. International Journal of Green Economics, 11(1), 1-14.

Azizi, F., Bagherzadeh, G., \& Mombeini, H. (2014). Relationship marketing strategy and customers' satisfaction in the third millennium organizations (case study: banking Industry). International Journal of Scientific Management and Development, 2(12), 728-732.

Belias, D., \& Koustelios, A. (2015). Leadership style, job satisfaction and organizational culture in the Greek banking organization. Journal of Management Research, 15(2), 101-110.

Caruana, A. (2002). Service loyalty. European journal of marketing.

Chen, H., Chiang, R. H., \& Storey, V. C. (2012). Business intelligence and analytics: From big data to big impact. MIS quarterly, 1165-1188.

Das, T. K., \& Teng, B.-S. (2002). Alliance constellations: A social exchange perspective. Academy of management review, 27(3), 445-456.

Eugene W. Anderson et al., (1994), customer satisfaction, market share, and profitability; findings from Sweden, Journal of marketing, vol.58

Faroughian, F. F., Kalafatis, S. P., Ledden, L., Samouel, P., \& Tsogas, M. H. (2012). Value and risk in business-to-business e-banking. Industrial Marketing Management, 41

Hair, J. F., Black, W. C., Babin, B. J., \& Anderson, R. E. (2010). Multivariate data analysis (7th ed.). New Jersey: Prentice Hall.

Hayes, A. F. (2009). Beyond Baron and Kenny: Statistical mediation analysis in the new millennium. Communication Monographs, 76(4), 408-420.

Huang, M.-H. (2015). The influence of relationship marketing investments on customer gratitude in retailing. Journal of Business Research, 68(6), 1318-1323.

Krejcie, V. R., \& Morgan, W.D. (1970). Determining sample size for research activities. Educational and Psychological Measurement, 30, 607-610.

Lima, M., \& Fernandes, T. (2015). Relationship bonds and customer loyalty: A study across different service contexts. Paper presented at the International Conference on Exploring Services Science.

Lin, P., Weng, J. C. M., Hsieh, Y. (2003). Relational bonds and customer's trust and commitment- a study on the moderating effects of web site usage. The Services Industries Journal 23 (3).

Lo, S. C. (2012). A study of relationship marketing on customer satisfaction. Journal of social sciences, 8(1), 91.

Luu, N., Ngo, L. V., \& Cadeaux, J. (2018). Value synergy and value asymmetry in relationship marketing practices. Industrial Marketing Management, 68, 165-176.

Matthews, D. R., Son, J., \& Watchravesringkan, K. (2014). An exploration of brand equity antecedents concerning brand loyalty: A cognitive, affective, and conative perspective. Journal of Business and Retail Management Research (JBRMR), 9(1), 26-39.

Mohsan, F., Nawaz, M. M., Khan, M. S., Shaukat, Z., \& Aslam, N. (2011). Impact of customer satisfaction on customer loyalty and intentions to switch: Evidence from banking sector of Pakistan. International Journal of Business and Social Science, 2(16). 
Mooij, M., \& Hofstede, G. (2010). The Hofstede model: Applications to global branding and advertising strategy and research. International Journal of advertising, 29(1), 85-110.

Morgan, R. M., \& Hunt, S. D. (1994). The Commitment-Trust Theory of Relationship Marketing. Journal of Marketing, 58(3), 20-38

Neuman, W. L. (2007). Basics of social research; Qualitative and quantitative approaches (2nd ed.). Boston, USA: Pearson Education, Inc.

Ruiz-Equihua, D., Romero, J., \& Casaló, L. V. (2020). Better the devil you know? The moderating role of brand familiarity and indulgence vs. restraint cultural dimension on eWOM influence in the hospitality industry. Journal of Hospitality Marketing \& Management, 29(3), 310-328.

Schuckert, M., Liu, X., \& Law, R. (2015). Hospitality and tourism online reviews: Recent trends and future directions. Journal of Travel \& Tourism Marketing, 32(5), 608-621.

Tigre, F., Gnoth, J., \& Deans, K. R. (2015). Localizing cultural values on tourism destination websites: The effects on users' willingness to travel and destination image. Journal of Travel Research, 54(4), 528542.

Uganda Bureau of Statistics-UBOS (2018). Annual report of 2018/2019. Kampala, Uganda: Author.

Uebersax, L., Hagenmüller, H., Hofmann, S., Gruenblatt, E., Müller, R., Vunjaknovakovic, G., . . Meinel, L. (2006). Effect of scaffold design on bone morphology in vitro. Tissue engineering, 12(12), 34173429.

Uganda owner's Hotel association report (2018).

Wilcox, P., Winn, S., \& Fyvie-Gauld, M. (2005). 'It was nothing to do with the university, it was just the people': the role of social support in the first-year experience of higher education. Studies in higher education, 30(6), 707-722.

Wilson, D. T. and S. A. Jantrania (1995). 'Measuring Value in Relationship Development', Proceedings of the 9th IMP Conference, Bath University, Bath.

\section{Biography of the Lead Author}

The lead author (Benon Nabimanya Muhumuza) is currently a PhD student at Moi University, studying Business management with a bias in marketing management. He is a holder of a degree of Master of Business Administration and a degree of Bachelor of Social Works and Public Administration. He is currently a Lecturer at Makerere University Business School in the department of marketing and management with over 20 years working experience in research, consultancy, and lecturing. His research interests are in the areas of marketing communication, relationship marketing and general management. 